\title{
Ideologias econômicas e democracia no Brasil *
}

\section{Luiz Carlos Bresser Pereira}

A transição para a democracia foi um longo processo no Brasil. Teve início em meados dos anos 70 e terminou somente no começo de 1985. Três anos mais tarde, no entanto, a maioria das pessoas acredita que o processo de democratização não está terminado. Raymundo Faoro disse recentemente que a transição para a democracia no Brasil está durando tanto que acábará sendo mais longa que o período do regime autoritário (FAORO, 1988, p.7). Compreendo este ponto de vista, mas não o aceito. A transição para a democracia terminou há três anos. Mas a democracia resultante é decepcionante, uma vez que não conseguiu solucionar os problemas econômicos e sociais que o País enfrenta. Em outras palavras, o regime político no Brasil é democrático, mas a democracia está muito longe de se consolidar. De fato, como o novo governo democrático tem se mostrado incapaz de superar os problemas econômicos e sociais existentes, surgiu uma nova crise política.

Num trabalho recente eu analisei a crise política hoje existente no Brasil uma crise de legitimidade e governabilidade - e a relacionei à inabilidade do governo Sarney em obter credibilidade e ser fiel ao pacto político modemo e democrático que uniu os trabalhadores, a classe média assalariada e os empresários em torno da luta contra o regime militar autoritário (BRESSER PEREIRA, 1986). Este foi um pacto entre as diversas classes do capital industrial moderno - o tipo predominante do capital no Brasil. O governo Sarney, entretanto, particularmente a partir de 1987, foi dominado pelos representantes de um tipo de capital mercantil, arcaico, formado por políticos e empresários dependentes dos favores do Estado. A incompatibilidade entre o governo central e as forças econômicas e ideo'ógicas hegemônicas no Brasil, bem como a inabilidade do governo em enfrentar a aguda crise econômica prevalecente hoje no Brasil produziram uma crise de legitimidade que põe em risco a nova democracia brasileira.

Neste trabalho farei uma abordagem complementar, na medida em que vou tentar analisar alguns obstáculos políticos e ideológicos para a consolidaçāo da democracia no Brasil. Proporei que o processo de democratização do País baseou-se em realidades sócio-econômicas sólidas e que foi uma conquista da sociedade civil e não um presente do regime militar. Tentarei também demonstrar que o processo de democratização não levou em conta, muito menos soube criticar, algumas ideologias e práticas políticas típicas de países subdesenvolvidos de renda média, como o Brasil: crenças nacionalistas anacrônicas

\footnotetext{
* Trabalho apresentado no seminário L'internacionalisation de la Democratié Politique,
} organizado pela Universidade de Montreal, 28 de setembro a 5 de outubro de 1988. 
da esquerda, demandas irrealistas por parte dos trabalhadores apoiadas em um distributivismo ingênuo, populismo e clientelismo por parte dos políticos oportunistas, conservadorismo, miopia e subordinação aos interesses externos das elites. Ora, estas ideologias e práticas políticas constituem-se em sérios obstáculos às políticas econômicas coerentes e progressistas, necessárias para se conseguir a retomada do crescimento e a estabilidade de preços.

A crise econômica no Brasil - definida pela estagnação da renda per capita desde 1980 e por taxas de inflaçáo extraordinariamente altas - foi, no início dos anos 80, a causa básica da derrota do regime autoritário, mas, hoje, como permanece sem solução, esta mesma crise econômica está ameaçando o novo regime democrático. Recessâo e altas taxas de inflação seráo sempre fatores de instabilidade para o regime estabelecido no poder, seja ele autoritário ou democrático. Ao final dos anos 80 , é a democracia que está sendo ameaçada pela crise econômica, uma vez que a maioria dos regimes políticos da América Latina são democráticos.

Neste trabalho não irei discutir a crise econômica, mas sim os problemas políticos que dificultam sua solução. É comum ouvir-se que a atual crise econômica brasileira tem origens políticas e que deveria ser solucionada na arena política. Não concordo com esta proposição. Acredito que as crises política e econômica hoje existentes no Brasil são autônomas embora interdependentes, mutuamente se influenciando. A crise econômica é mais antiga, suas origens podem ser encontradas no final dos anos 70 . A crise política, na sua forma atual, é um fenómeno da segunda metade dos anos 80; está definida pela inabilidade do governo Sarney e, mais amplamente, da elite brasileira, em enfrentar o desafio de estabelecer no Brasil instituiçōes e práticas políticas e ideológicas coerentes com um capitalismo moderno e democrático.

Dizer que os problemas econômicos têm origens políticas ou que sua solução depende somente da vontade política é reduzir a política econômica (através da qual a política se expressaria) a uma engenharia social todo-poderosa. O nome original e mais correto da ciência econômica - economia política - ressaltava o caráter social e político do processo econômico. Mas isto não justifica uma transformação dos problemas econômicos reais em problemas políticos, ou dizer que a crise econômica que o Brasil enfrenta hoje será superada contanto que se encontre uma solução adequada para os problemas políticos. Há aqui uma contradição curiosa, porque os economistas conservadores, que defendem a neutralidade política e ideológica da economia positiva, são exatamente os

A crise económica no Brasil - definida pela estagnação da renda per capita desde 1980 e por taxas de inflaçäo extraordinariamente altas - foi, no início dos anos 80, a causa básica da derrota do regime autoritário, mas, hoje, como permanece sem solução, esta mesma crise econômica está ameaçando o novo regime democrático. que dizem que os problemas económicos podem ser facilmente solucionados por meios políticos. Os obstáculos políticos às políticas econômicas coerentes têm uma importância enorme, mas sua solução não garante que os problemas econômicos serão resolvidos com êxito.

A consolidação da democracia no Brasil depende da superação da atual crise, tanto econômica como política. Simon Schwartzman observou que é um "mito político" acreditar-se que os regimes democráticos são mais eficientes que os regimes autoritários em produzir benefícios sociais e económicos (SCHWARTZMAN, 1988, p.4). É verdade. A democracia não deve ser considerada como um meio, mas como um fim em si mesma. Mas $\epsilon$ tambem verdade que o processo de redemocratizaçāo provocou grandes expectativas em função desse mito. Agora, a inabilidade do novo regime democrático em gerenciar o 
problema econômico e social no Brasil é uma fonte de desapontamento, representando uma ameaça maior para a consolidação da democracia. Neste trabalho tentarei compreender porque isto está ocorrendo, procurando definir os obstáculos políticos e ideológicos a uma política econômica reformista e racional, a qual se constitui em fator essencial para a consolidação da democracia no Brasil.

\section{O Processo de Redemocratização}

O processo de redemocratização que ocorreu no País entre meados dos anos 70 e 1984 foi o resultado de um profundo processo político. A democracia resultante não é um presente ou uma concessão do regime militar, mas sim uma conquista da sociedade civil. Baseou-se na consolidação de um tipo moderno de capitalismo, que dispensa o uso da violência direta para apropriação do excedente.

Há, de fato, duas interpretações opostas para o processo de redemocratizaçāo no Brasil. Pode-se dizer,.primeiro, que a distensāo de Geisel, e, segundo, a abertura de Figueiredo demonstram que o processo de redemocratização foi uma iniciativa do regime militar; a sociedade civil pode ter tido algum papel ao protestar ou pressionar pela democracia, mas o processo de redemocratização foi essencialmente o resultado de uma estratégia política do regime autoritário (MARTINS, 1983; DINIZ, 1985). Minha interpretação dirige-se no sentido contrário (BRESSER PEREIRA, 1978; 1985). O que de fato ocorreu no Brasil foi um processo dialético entre a redemocratização exigida pela sociedade civil e a lenta estratégia de abertura conduzida pelo regime militar. $O$ processo de redemocratização, que contou desde o golpe de 1964 com o apoio dos trabalhadores e da classe média assalariada e intelectualizada (tecnoburocracia democrática), recebeu a decisiva adesão da burguesia (mais especificamente dos empresários líderes) em torno de 1977. Foi este apoio que fortaleceu o processo de redemocratização, mas foi também o fator que, conduzindo a uma transição conservadora (WEFFORT, 1984), levou alguns analistas a afirmarem que a transiçāo não ocorreu efetivamente (FERNANDES, 1986).

Esses analistas nāo estão certos. Eles são vítimas de seu natural desapontamento com o novo regime democrático. $O$ processo de redemocratização ocorreu efetivamente. $O$ fato de o novo presidente não ter sido eleito diretamente pelo povo é importante mas não essencial. Os fatos são que nós tivemos eleiçōes livres em 1986, a imprensa e a formação de partidos políticos são livres, o poder judiciário está trabalhando com independência, o Congresso acaba de redigir uma nova Constituição que foi livremente debatida e aprovada; uma constituição que não é um sonho, que é muito conservadora para a esquerda e muito progressista para a direita, mas que é de fato o melhor compromisso que a sociedade brasileira poderia produzir nos dias de hoje. Por todas essas razōes, nós realmente temos um regime democrático no Brasil e uma nova constituição que, apesar das falhas que a ela atribuímos, é um fator positivo para a consolidação da democracia no Brasil.

Eu sei muito bem que esta nova democracia não trouxe nem desenvolvimento econômico nem justiça social para o País. Mas é importante não ampliar o conceito de democracia, incluindo nele todos os nossos objetivos. A democracia é um tipo de regime político, e não uma utopia. A democracia não é ne-
O processo de redemocratização que ocorreu no País entre meados dos anos $70 \mathrm{e}$ 1984 foi o resultado de um profundo processo político. A democracia resultante não um presente ou uma concessäo do regime milltar, mas sim uma conquista da sociedade civil. 
cessariamente o meio mais eficiente para o desenvolvimento econômico e a justiça social. Historicamente, "a democracia surgiu como uma adição tardia à sociedade de mercado competitivo e ao estado liberal(...) foi uma tentativa por parte da classe mais baixa de conseguir seu lugar justo e totalmente competitivo dentro daquelas instituições e aquele sistema de sociedade" (MACPHERSON, 1966, p.10-11).

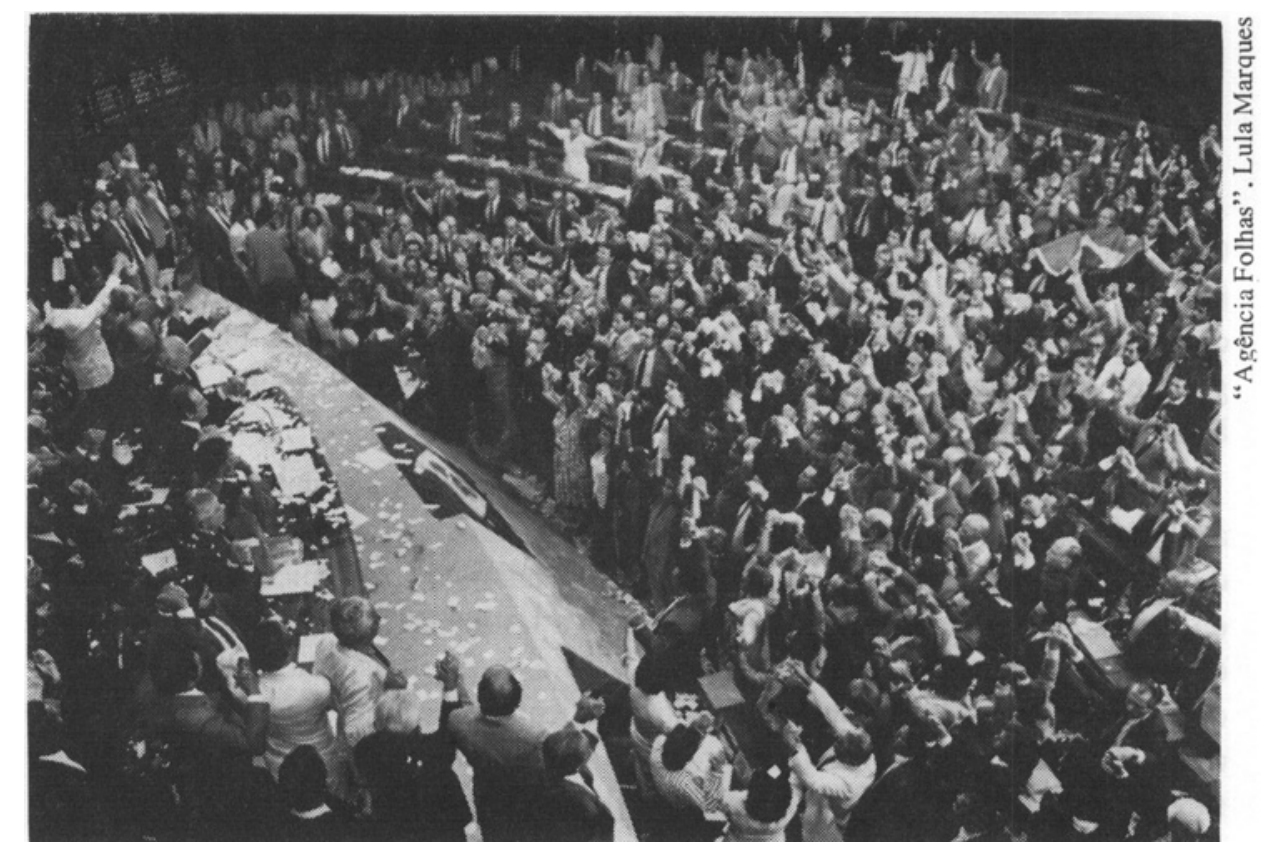

Podemos ter regimes autoritários que obtêm grande êxito em promover desenvolvimento econômico - foi o caso do Brasil durante boa parte do período autoritário - e em produzir uma distribuição mais igualitária da renda (veja, por exemplo, as formações estatistas contemporâneas que têm como protótipo a União Soviética). $\mathrm{Na}$ verdade a democracia se justifica por ela mesma. A democracia, o crescimento econômico e a distribuição mais uniforme da renda devem ser os objetivos finais de toda sociedade.

Certamente podemos considerar cada um desses objetivos como relacionado com os demais. É mais fácil, por exemplo, manter a democracia quando o País está crescendo, e espero que o contrário também seja verdade. O crescimento, a estabilidade dos preços e a distribuição da renda são fatores primordiais na consolidação da democracia. Mas não faz sentido confundir democracia com desenvolvimento econômico ou com uma distribuição mais uniforme da renda.

\section{Ideologias da Esquerda Moderada}

A democracia no Brasil é mais sólida e arraigada ao sistema econômico e social do que normalmente se pensa. As razões por trás desta proposição poderiam ser sintetizadas desta forma:

1) o capitalismo industrial moderno consegue apropriar excedentes econômicos através do mercado, dispensando o uso de força direta necessária nas sociedades pré-capitalistas e mercantilistas; 
2) a burguesia não se sente ameaçada pela esquerda;

3) a esquerda revolucionária está em crise no mundo todo e em particular na América Latina, e, desta forma, não tem um projeto revolucionário que pudesse ameaçar a hegemonia da burguesia;

4) o mesmo pode-se dizer dos militares, e, de forma mais ampla, dos autoritários: eles não têm um projeto alternativo; estão tão perplexos com a crise econômica e política quanto a burguesia;

5) os Estados Unidos já não incluem mais os golpes de estado em sua estratégia para consolidar o capitalismo na América Latina.

Não se pode dizer, entretanto, que a democracia esteja consolidada. O'DONNELL (1988, p.85) salientou que dada a improbabilidade de um golpe militar, a "morte lenta" da democracia - isto é, um processo de contínua perda de efetividade e credibilidade das instituições políticas devido ao fracasso do governo em enfrentar os problemas sociais e econômicos - é uma outra possibilidade.

A incapacidade governamental ao enfrentar esses problemas não pode ser atribuída exclusivamente às limitaçôes pessoais dos governantes, nem à enorme dimensão dos obstáculos econômicos. Os obstáculos econômicos são sem dúvida imensos. Não é por acaso que a América Latina está estagnada há dez anos, desde que se desencadeou a crise da dívida externa. Mas esta incapacidade pode e deve também ser explicáda pelas práticas políticas e ideológicas não predispostas à adoção das políticas econômicas corajosas, coerentes e firmes que são necessárias.

Examinemos estas ideologias e práticas políticas. Irei classificá-las segundo suas origens:

1) na esquerda moderada;

2) na direita oportunista;

3) na direita ideológica.

Começarei pela esquerda moderada. Embora me sinta pessoalmente identificado com este grupo, estou há muito tempo convencido de que uma tarefa essencial hoje em dia é a de criticar o anacronismo de algumas idéias da esquerda. Nos anos 50 eu estava engajado na luta pela industrialização via substituição de importaçōes e intervenção moderada do Estado, mas já na década de 60 chamava a atenção para os fatos históricos relacionados à modernização do capitalismo que exigiam uma nova interpretação do Brasil (BRESSER PEREIRA, 1968 , cap. 5, e 1983). Esta esquerda moderada criticava severamente as políticas econômicas ortodoxas do regime autoritário. Às vezes fazia-o corretamente, mas em outras ocasióes estava apenas repetindo slogans fora de moda, que poderiam fazer sentido nos anos 50 , mas não mais nos anos 80 . Vamos rever estas idéias.

\section{Nacionalismo ultrapassado}

Nas décadas de 40 e 50 a esquerda desenvolveu a tese de que o imperialismo estava aliado ao capital agromercantil para evitar a industrialização. Os altos investimentos das multinacionais na indústria manufatureira desde meados
Em meados dos anos 60 o regime autoritário decidiu por uma estratégia de desenvolvimento voltada para as exportações. Foi uma decisão acertada, embora tenha tido a conseqüência perversa a curto prazo de compatibilizar taxas sustentadas de demanda interna com concentração de renda. 
dos anos 50 provaram que, se a tese esteve correta no passado, deixou de ser legítima desde então (CARDOSO e FALETTO, 1970). Mas ainda hoje temos nacionalistas pensando em termos de anos 50. Eles não entendem que ser nacionalista nos dias de hoje é, antes de mais nada, combater a tentativa irracional de pagar integralmente a dívida externa, ou empenhar-se pelo desenvolvimento do progresso tecnológico e científico autônomo dentro do País, é, em outras palavras, ter uma clara noçāo do que seja o interesse nacional, ao invés de opor-se às multinacionais, que contribuem de forma efetiva para o crescimento econômico do País.

\section{Orientação no sentido do mercado interno}

Em meados dos anos 60 o regime autoritário decidiu-se por uma estratégia de desenvolvimento voltada para as exportaçōes. Foi uma decisão acertada, embora tenha tido a consequêencia perversa a curto prazo de compatibilizar taxas sustentadas de demanda interna com concentração de renda 1 . A esquerda moderada se opôs a esse procedimento desde o início, sem saber que o padrão alternativo de crescimento, baseado em projetos de substituição de exportaçōes altamente intensivos em capital, além de ter esgotado suas virtualidades como um modelo de crescimento no início da década de 60 , concentra muito mais renda no longo prazo do que uma estratégia de crescimento baseada em exportaçōes de bens manufaturados intensivos em mão-de-obra.

Nos anos 70 a esquerda costumava criticar Formosa e a Coréia como sendo meras plataformas de exportação, enquanto que um dos intelectuais da direita ideológica no Brasil, Roberto Campos, pretendia que esses países fossem exemplos de sociedades liberais. Hoje em dia sabemos que esses países desenvolveram uma grande indústria apoiada em um Estado com forte capacidade de intervenção e um claro sentido do interesse nacional, que tiveram um enorme aumento de produtividade ao buscarem aumentar sua competitividade internacional através de uma estratégia de desenvolvimento voltado para as exportações, e que apresentam uma distribuição de renda muito mais uniforme do que - Brasil. A reforma agrária promovida nesses países logo após a Segunda Guerra foi uma causa dessa melhor distribuição de renda; a outra foi a política de crescimento voltado para as exportaçōes.

\section{Não às políticas de ajustamento}

Esta é a conseqüencia de um desenvolvimentismo arraigado - e não devidamente revisto quando isto se tornou necessário - que caracterizou os estruturalistas latino-americanos, inclusive este autor, nos anos 50 . Criticamos duramente o ajustamento da década de 60 . $O$ fato desse ajustamento ter-se baseado quase que exclusivamente na redução dos salários (LARA REZENDE, 1982) foi uma boa razão para críticas. Mas a esquerda baseou seu desacordo quase que somente no slogan "não à recessão", e ao fazê-lo incorreu no populismo. Em 1979, quando o ajustamento se fazia absolutamente necessário, a irrespon-

1 Examinei esta questão pela primeira vez ainda em 1970, quando a esquerda insistia em falar em estagnação apesar do enorme crescimento econômico que estava ocorrendo, no artigo: "Dividir ou Multiplicar?" publicado na Visão (novembro, 1970). Depois examinei extensamente o problema em Estado e subdesenvolvimento industrializado (1977). 
sável política desenvolvimentista e populista - porque o populismo é tanto de esquerda quanto de direita - do Ministério do Planejamento do regime autoritário foi apoiado por economistas da esquerda estruturalista moderada. Quando em 1981, afinal, o ajustamento teve início, a idéia básica da esquerda era de que essa medida nâo era necessária, quando na realidade o era. Naquele momento era de fato impossível - além de indesejável - tentar manter altos déficits comerciais. A única crítica séria e inovadora às políticas ortodoxas de ajustamento originou-se na esquerda moderada a partir dos economistas que desenvolveram a teoria da inflação inercial ${ }^{2}$.

\section{Distributivismo salarial}

Um problema gravíssimo no Brasil é a concentração de renda. Temos aqui uma das mais desequilibradas e injustas distribuiçōes de renda do mundo, mas este fato não legitima um distributivismo salarial irrealista. Uma política econômica progressista no Brasil terá, necessariamente, como objetivo principal conseguir uma distribuição menos desigual da renda, mas ao mesmo tempo terá de acautelar-se contra a elevação dos salários reais acima dos níveis de produtividade. Sempre que se tentar descumprir essa regra, os lucros estarão ameaçados e a aceleração da taxa de inflação será inevitável. Na verdade, a política salarial deveria limitar-se a três objetivos: proteger o salário real da inflação, assegurar a transferência das elevaçōes na produtividade para os trabalhadores e reduzir as diferenças salariais através do aumento gradual do salário mínimo. Sem dúvida é possível aumentar os salários mais do que a produtividade sem afetar os lucros dos setores produtivos, desde que se logre reduzir os rendimentos dos rentistas ou então desde que se reduzam os impostos em função do aumento da eficiência do Estado. Estas estratégias, entretanto, são de difícil execução. Formas de distribuir a renda entre salários e lucros mais eficientes do que o aumento dos salários acima da produtividade incluem uma política de investimentos voltada para bens trabalho-intensivos, a reforma agrária, uma reforma tributária progressiva e a orientação das despesas públicas para os pobres.

Estas idéias, no entanto, não são comumente aceitas na esquerda populista. O slogan "os aumentos salariais não são uma causa da inflaçāo" é usado com freqüência. Durante um bom tempo, no período do regime autoritário, esta frase correspondeu à realidade, uma vez que os salários reais dificilmente se elevavam a níveis superiores ao aumento da produtividade. Em certos momentos foram, inclusive, reduzidos em termos absolutos. Mas, no final dos anos 70 começamos a ver um quadro diferente. $E$, depois da derrota do regime autoritário em 1984, as demandas irrealistas por parte dos trabalhadores, particularmente por parte da classe média assalariada empregada no setor público, aumentaram acentuadamente. $O$ acirramento do conflito distributivo causou a aceleração da inflação, tanto diretamente (inflação de custos) como através da elevação do déficit público. Contudo, dada a aceleração da inflação, os aumentos reais de salários tenderam a ter vida curta; em pouco tempo a inflação mais elevada eliminava os aumentos reais de salários conseguidos geralmente

Um problema gravíssimo no Brasil é a concentração de renda. Temos aqui uma das mais desequilibradas e injustas distribuições de renda do mundo, mas este fato não legitima um distributivismo salarial irrealista.

2 Uma resenha da teoria da inflação inercial encontra-se em Bresser Pereira, 1986: "Inflação inercial e Plano Cruzado". 
depois de intensa luta sindical. $O$ único resultado duradouro foi uma taxa mais elevada de inflação.

Concluindo, algumas idéias e práticas políticas da esquerda moderada - o nacionalismo ultrapassado, a ideologia do mercado interno, a recusa às políticas de ajustamento e o distributivismo salarial - não são mais compatíveis com políticas econômicas racionais e coerentes. Elas representam um obstáculo para o crescimento e para a estabilidade de preços, e, portanto, para a consolidação da democracia no Brasil.

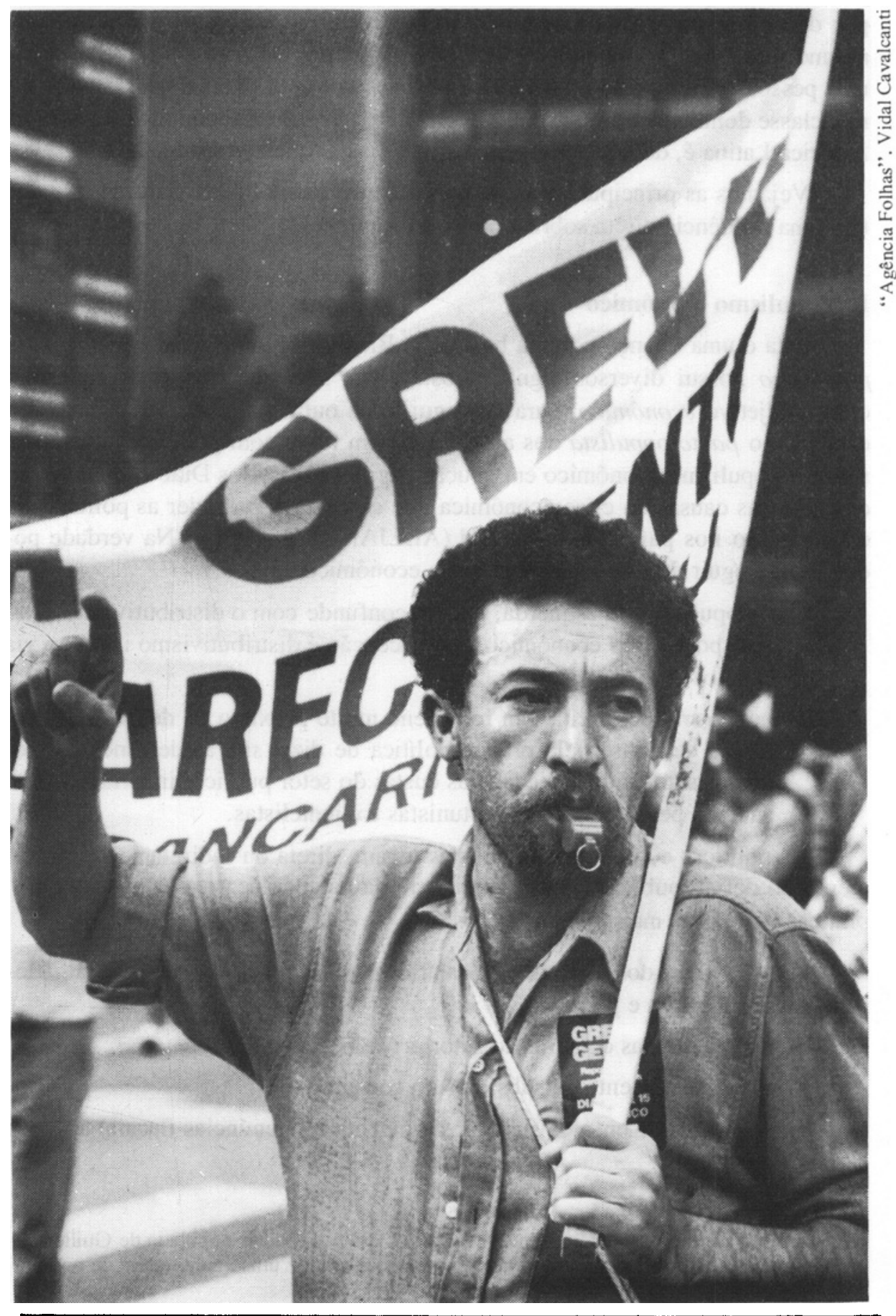




\section{Ideologias da Direita Oportunista}

Diferentes, mas afinal conduzindo aos mesmos resultados, são as práticas políticas e ideológicas da direita moderada oportunista e da direita moderada ideológica. Esta última se autodenomina "centro" no Brasil, mas o conceito de centro não faz sentido em ciência política. É apenas um disfarce dos representantes da direita, que no Brasil não gostam de serem chamados de direitistas ou conservadores. Por outro lado, a direita oportunista faz parte da direita simplesmente porque o Brasil é um país capitalista. Na verdade, um oportunista é, por definição, um político sem conviç̧ōes ideológicas. Num país capitalista, mesmo que finja ou pretenda pertencer à esquerda, ele será em última análise uma pessoa de direita, pois fará todas as concessōes possíveis e imagináveis para a classe dominante. Neste sentido, uma parte da autodenominada esquerda na América Latina é, de fato, de direita na medida em que é oportunista.

Vejamos as principais práticas políticas dos oportunistas. São práticas que têm uma influência direta sobre a política econômica.

\section{Populismo econômico}

Esta é uma doença política básica no Brasil. Sei muito bem que a palavra populismo possui diversos significados. É por isso que qualifico populismo com o adjetivo econômico, para distingui-lo de outros significados, como, por exemplo, o pacto populista dos anos 50. Quem falou com grande competência sobre o populismo econômico em poucas páginas foi Carlos Diaz Alejandro, ao descrever as causas da crise econômica que costumava preceder as políticas de estabilização nos países do Cone Sul (ALEJANDRO, 1981) ${ }^{3}$. Na verdade podemos distinguir dois tipos de populismo econômico:

1) o populismo de esquerda, que se confunde com o distributivismo salarial; populismo econômico nesta acepção é distributivismo ingênuo via salários;

2) populismo de direita, um fenômeno muito próximo do desenvolvimentismo; define-se pela prática política de dizer sim às demandas de todos os setores da sociedade às custas do setor público, invariavelmente adotada pelos políticos oportunistas e clientelistas.

As políticas econômicas populistas levam, direta ou indiretamente, ao aumento do déficit público e ao desequilíbrio da balança de pagamentos. Entre as práticas populistas mais comuns temos:

a) a elevação dos ordenados e salários dos funcionários e dos trabalhadores públicos e privados;

b) o aumento das compras ao setor privado;

c) o. estabelecimento de subsídios ao consumo;

d) o estabelecimento de subsídios e incentivos (renúncias fiscais) ao setor privado;

3 Ver também a contribuição pioneira sobre o ciclo econômico populista de Guillermo O’Donnell (1977). Este, embora um cientista político, fez uma análise além de política também econômica do ciclo populista. 
e) a valorização artificial da moeda local;

f) o aumento dos créditos subsidiados através dos bancos oficiais estão entre as práticas populitas mais comuns. Beneficiam aparentemente a todos - a funcionários, empresários e trabalhadores.

O resultado do populismo é o ciclo populista. No primeiro momento o governo adota uma combinação das seguintes medidas: eleva os salários dos funcionários públicos e facilita o aumento dos salários do setor privado, aumenta as despesas públicas, valoriza a moeda local ao atrasar as desvalorizações nominais da taxa de câmbio, mantém artificialmente baixa a taxa interna de juros, e segura artificialmente os preços do setor público. Em conseqüência temos a elevação do consumo e dos investimentos, a aceleração da taxa de crescimento e uma inflaçāo declinante em função da valorização cambial e do atraso dos preços públicos. É o momentâneo paraíso. Mas logo as distorções provocadas por estas práticas se manifestam. Aparecem os desequilibrios no balanço de pagamentos na medida em que os exportadores suspendem suas exportaçōes e os importadores aumentam suas compras. A inflação volta a se acelerar, muitas vezes de forma dramática. $O$ ciclo termina geralmente com uma mudança radical na política econômica freqüentemente precedida por uma grave crise e pela mudança dos ministros responsáveis, senão por um golpe de Estado. As políticas expansionistas de 1979/80 (provavelmente o pior erro na história da política econômica no Brasil) e do Plano Cruzado (um plano excelente, uma oportunidade perdida em função de uma administração incompetente) são exemplos típicos do ciclo populista no Brasil, o primeiro, proveniente da direita sob Delfim Netto, e o segundo, tendo por origem setores progressistas.

\section{Clientelismo}

Esta é uma prática política no meio do caminho entre populismo e mera corrupção. As três práticas implicam no uso de fundos públicos. No caso do populismo, temos uma forma impessoal de se assegurar a boa vontade dos grupos ou comunidades beneficiadas pela despesa pública; no caso da corrupção, estamos diante de uma forma pessoal e direta de enriquecimento às custas do erário público; no caso do clientelismo, temos numa forma intermediária entre os dois casos anteriores, uma forma semipessoal de uso dos fundos públicos beneficiando diretamente eleitores potenciais e indiretamente $o$ autor da prática clientelística. No Brasil inventou-se uma palavra nova e muito expressiva para significar clientelismo: fisiologismo. O político fisiológico é um oportunista por definição. É uma pessoa que transforma a política em um negócio como qualquer outro - em um negócio em que o político usa seu poder político para realizar trocas, para prestar e receber favores. É um fisiológico porque coloca os interesses pessoais e materiais acima das idéias, acima dos princípios e valores morais que deveriam presidir a ação política.

No Brasil inventou-se uma palavra nova e muito expressiva para significar clientelismo: fisiologismo. $\mathbf{O}$ polftico fisiológico é um oportunista por definiçāo.
Estas duas práticas políticas oportunistas estão profundamente arraigadas no sistema político brasileiro. São uma conseqüência do baixo nível de cidadania do povo. A desinformação, a educação precária, a desconfiança em relação aos candidatos populares são características típicas do eleitor médio brasileiro. Desta forma, nas palavras de WANDERLEY REIS (1988, p. 24), "dificilmente se poderia pretender que, nas condições que caracterizam o eleitorado brasileiro, a estabilização do jogo democrático viesse a ocorrer em torno de partidos 
ideológicos(...) o processo de agregação partidária de interesses continuará provavelmente a dar-se entre nós através de partidos que combinem o clientelismo tradicional com um apelo eleitoral de tonalidades populistas".

\section{Ideologias da Direita Conservadora}

A direita ideológica é também uma fonte importante de política econômica irracional. Nesta categoria estão incluídos os economistas neoclássicos ou monetaristas que adotam uma posição teórica militante contra praticamente qualquer tipo de intervenção do Estado na economia. Boa parte da elite empresarial brasileira deve também ser incluída nesta categoria. Seus líderes não são oportunistas, mas ideologicamente conservadores. E nos países em desenvolvimento o conservadorismo - além de colocar a ordem acima da justiça social, além de resistir a mudanças, como ocorre em todos os conservadorismos - significa subordinação ideológica ao sistena de valores e crenças dominantes nos países centrais.

Os membros desta corrente estão verdadeiramente convencidos de que suas visões sobre política econômica são intrinsicamente racionais. A lógica do capitalismo e sua própria lógica seriam, ambas, pura racionalidade - uma racionalidade que confrontam com a irracionalidade da esquerda e dos políticos oportunistas. Dado seu controle sobre os meios de comunicaçāo, eles conseguem habilmente veicular estas idéias para a sociedade, e, assim, reforçar sua hegemonia ideológica.

$\mathrm{Na}$ verdade, suas idéias estão muito longe de serem racionalidade pura, e representam um obstáculo da maior importância à adoção de uma política econômica coerente no Brasil, especialmente em um momento em que é necessário coragem na tomada de decisões econômicas. Vejamos estas ideologias e práticas políticas da direita ideológica:

\section{Conservadorismo social}

Este é um problema óbvio em um país onde a concentração de renda é surpreendentemente alta. A carga fiscal é relativamente baixa e o sistema tributário muito regressivo no Brasil. Assim, uma reforma fiscal progressiva é um instrumento óbvio para reduzir o déficit público e melhorar a distribuição da renda. A direita ideológica se opõe sistematicamente a reformas fiscais que elevem a carga fiscal ou a tornem mais progressiva. Os argumentos que usa vão desde a negação de que a carga tributária seja baixa no Brasil até preocupações quanto ao desestímulo à poupança e ao investimento. Em contrapartida, os subsídios e os incentivos fiscais às empresas são uma fonte por excelência de desequilíbrio orçamentário; a maioria deles perdeu sua raison d'être há muito tempo; e todavia a eliminação dos subsídios e das renúncias fiscais encontra sempre a oposição por parte de seus beneficiários. Sem dúvida a direita ideológica está formalmente preocupada com a concentração da renda no Brasil, mas nada faz para resolver o problema; ela sabe que um pacto social, que seria essencial para controlar os salários e cortar a inflação, não pode ser implementado sem concessões aos trabalhadores em termos de reformas sociais, mas, via de regra, tende a se opor a essas reformas. Age assim não apenas em função de

A direita ideológica é também uma fonte importante de política econômica irracional. Nesta categoria estão incluídos os economistas neoclássicos ou monetaristas que adotam uma posição teórica militante contra praticamente qualquer tipo de intervenção do Estado na economia. 
seus interesses de classes mas a partir de sua profunda convicção que a ordem tem prioridade sobre a justiça. Que jamais se pode arriscar a ordem em nome de mais justiça social.

\section{Monetarismo}

Esta foi uma contra-revolução conservadora contra o keynesianismo, que aparece em sua forma original na versão de Friedman e desenvolve-se através da teoria das expectativas racionais dos "novos clássicos" - Sargent, Lucas. Baseia-se em uma contradiçāo fundamental: é uma teoria macroeconômica necessariamente voltada para a política econômica (a política econômica tornouse inevitável a partir da revolução keynesiana), que, no entanto, postula a abstinência radical de intervenção estatal. Na verdade essa abstinência não é posta em prática, primeiro, porque as políticas econômicas recomendadas pelo monetarismo para alcançar a estabilização - a partir da qual se poderia praticar aquela abstinência - devem ser muito ativas; segundo, porque a estabilização, quando alcançada, é sempre muito precária, exigindo uma contínua intervenção do Estado para tentar mantê-la.

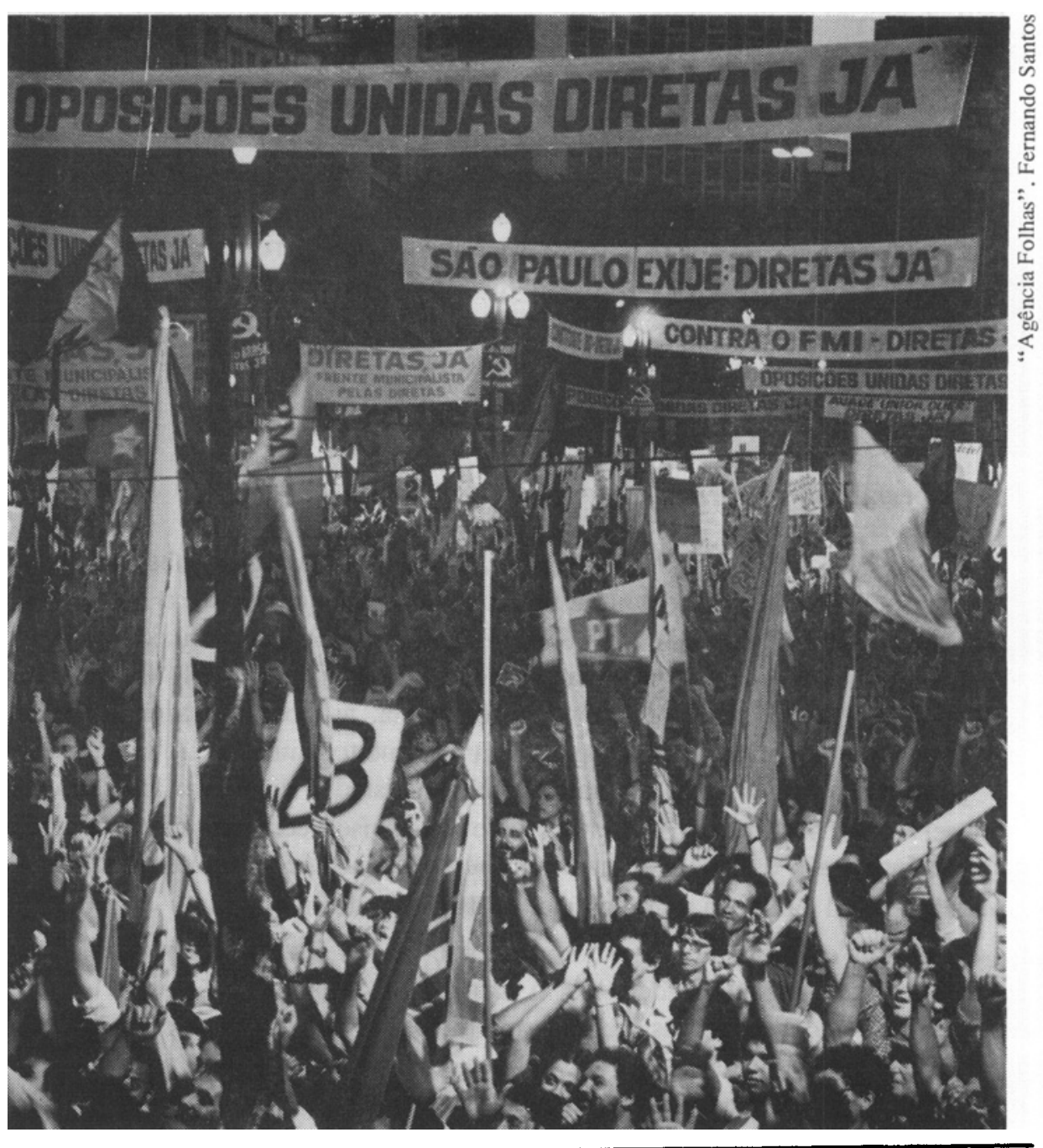


Atualmente o monetarismo é uma religião econômica dos países capitalistas desenvolvidos. Dada a subordinação ideológica ao centro das elites nos países periféricos, é adotado quase que sem restrições pela direita ideológica em um país periférico como o Brasil. Dois exemplos: a inflação no Brasil tem origens estruturais e um caráter inercial, mas acredita-se que ela pode ser controlada através somente da adoção de políticas fiscais e monetárias. Os desequilíbrios econômicos em uma economia subdesenvolvida como a brasileira são muito profundos, mas, apoiada no monetarismo, a direita ideológica acredita que as forças de mercado seräo capazes de resolver todos os problemas.

Os fracassos sucessivos desta estratégia para enfrentar as crises econômicas na Argentina, no Brasil e no Chile levaram o monetarismo a um certo grau de descrédito no início dos anos 80, mas depois do fracasso dos heterodoxos planos, Austral e Cruzado, o monetarismo recuperou parte de seu prestígio. Repentinamente, como resultado de um manobra ideológica muito interessante da direita ideológica, as políticas convencionais de estabilização sobre as quais há um relativo consenso entre os bons economistas, as políticas econômicas coerentes e racionais, portanto, foram identificadas com o monetarismo ortodoxo e contrapostas ao keynesianismo e à heterodoxia estruturalista, quando, de fato, a adoção de uma grande parte dessas políticas é partilhada por economistas de todas as escolas.

$\mathrm{Na}$ verdade, as políticas econômicas especificamente monetaristas são freqüentemente inadequadas ou francamente irracionais. $\mathrm{O}$ caráter ideológico e dogmático da recusa à intervenção estatal, inclusive à zegulação macroeconômica, torna evidentemente uma política econômica monetarista muito limitada. Por outro lado, há uma tendência fundamental no monetarismo de desconsiderar as características específicas da economia do País, em nome de uma pretensa universalidade da teoria econômica. Não há dúvida de que essa universalidade existe, mas seus limites históricos e geográficos devem estar sempre presentes aos economistas.

\section{Liberalismo grosseiro}

É o complemento do monetarismo. A direita ideológica sabe, ou deveria saber, que o Estado desempenhou um papel da maior importância na industrialização do Brasil. Mas nos anos 80 o Estado brasileiro foi reduzido a uma situação falimentar, vítima de uma gravíssima crise fiscal (WERNECK, 1987; BRESSER PEREIRA, 1987). Em conseqüência, as possibilidades de colocar em prática uma política industrial tornaram-se muito limitadas. A indústria tem hoje muito pouco a obter adicionalmente do Estado. Por outro lado, o credo conservador, neoliberal, predomina hoje nos países centrais industrializados. Dessa forma não é difícil entender porque os slogans neoliberais contra a intervençāo estatal passaram a predominar no Brasil também.

O País enfrenta atualmente a pior crise de sua história econômica. A renda per capita estagnou desde 1980. A causa maior desta situação é a crise fiscal do Estado. São necessárias medidas muito fortes para resolver este desequilíbrio financeiro estrutural do setor público, que tornou negativa a poupança do setor público, reduzindo dramaticamente sua capacidade de investimento. A direita ideológica, no entanto, minimiza o problema ao falar em déficit público 
quando temos uma crise fiscal, ao propor a demissão de alguns funcionários públicos ou então a imaginar que a solução para tudo é a privatização, quando decisões muito mais drásticas e abrangentes são necessárias (inclusive medidas de desregulaçāo e privatizaçāo). E coloca-se sempre e invariavelmente contra a intervenção do Estado (contra a estatização), quando o problema real é, através de políticas fiscais muito fortes e da estratégia de privatização, recuperar e relormar o setor público, que foi levado ao inchaço e à falência, entre outras causas, devido aos grandes subsídios e incentivos que concedeu e ainda concede ao setor privado.

\section{Internacionalismo subordinado}

Uma intemacionalização maior da economia brasileira é uma aspiração natural da elite empresarial local. $\mathrm{Na}$ verdade, o que ela quer é uma integração mais profunda da economia e da sociedade brasileiras ao Primeiro Mundo, do qual quer fazer parte. Entende que esta integraçāo tornará o capitalismo brasileiro econômica e ideologicamente menos vulnerável. Não discutirei esses objetivos. Acredito que são perfeitamente coerentes. Caso haja, como é minha convicção, uma clara hegemonia econômica e ideológica da burguesia, caso o capitalismo esteja bem estabelecido no Brasil, este desejo de uma integração maior com o mundo desenvolvido é bastante natural.

O problema é saber como alcançar essa integração. Muito freqüentemente esse internacionalismo toma a forma de uma subordinaçāo pouco crítica aos interesses dos países desenvolvidos. Esta atitude, que proponho chamar de internacionalismo subordinado, é um fenômeno da vida cotidiana no Brasil. É uma conseqüência da dominação econômica e cultural que o mundo desenvolvido central exerce sobre sua periferia. Mas, no caso da direita ideológica, esta subordinaçāo assume um caráter militante, tāo incompatível com os interesses nacionais quanto o velho nacionalismo da esquerda.

O exemplo mais dramático deste internacionalismo subordinado é a visāo adotada pela direita ideológica no tocante à dívida externa. A dívida externa é a causa isolada mais importante da estagnação e das altas taxas de inflação que prevalecem no Brasil desde o início da década de 80. A dívida externa reduziu a capacidade de poupança do País ao obrigá-lo a realizar enormes transferências de recursos reais; elevou o déficit público, pois mais de $80 \%$ da dívida externa são públicos, devendo seus respectivos juros serem pagos pelo governo; acelerou o processo inflacionário devido à elevação do déficit público e à

Uma internacionalização maior da economia brasileira é uma aspiração natural da elite empresarial local. Na verdade, o que ela quer $\boldsymbol{\epsilon}$ uma integraçăo mais profunda da economia e da sociedade brasileiras ao Primeiro Mundo, do qual quer fazer parte. desvalorização real da moeda local e reduziu os investimentos em função da redução da poupança bem como da elevação da taxa de juros internos que provocou.

A dívida externa brasileira é claramente muito alta e não pode ser paga. Uma redução na dívida é condição necessária para a superação da estagnação e da inflação. A alternativa seria uma enorme redução do consumo interno, que não é nem viável nem desejável (BRESSER PEREIRA, 1988). A direita ideológica, no entanto, não reconhece esses fatos. Dado que seu maior objetivo é fazer com que o Brasil se integre no Primeiro Mundo, ela rejeita qualquer tipo de confronto com os banqueiros, porque teme que as medidas unilaterais, que o País deverá tomar para poder negociar a partir de uma posição forte a redução 
de sua dívida externa, comprometam a desejada integração no Primeiro Mundo. O que a direita ideológica nāo compreende é que esta integração só será alcançada se o crescimento for retomado e a estabilidade de preços, atingida. Neste momento há uma incompatibilidade básica entre o pagamento integral dos juros sobre a dívida e o crescimento com estabilidade de preços. Desta forma, um certo grau de confronto com os bancos é condição necessária para uma futura integração da economia brasileira no sistema econômico capitalista internacional.

\section{Políticas Econômicas para a Consolidação da Democracia}

Os autoritários e os conservadores na América Latina apresentam o Chile hoje como exemplo de política econômica coerente, racional. Têm como argumento os níveis muito baixos de inflação e as taxas positivas de crescimento desde 1984. Não mencionam que a renda per capita ao final de 1987 estava 2,5\% abaixo do nível de 1980, que em 1987 os salários estavam $6 \%$ abaixo do nível de 1980 (PIEDRA, 1988), não mencionam que a concentração de renda e a pobreza aumentaram, esquecem que a economia chilena está sendo totalmente desnacionalizada na medida em que os ativos locais estāo sendo permutados pela dívida externa em termos desfavoráveis. Nas palavras de Miguel Urbano RODRIGUES (1988, p.3), "nos últimos quinze anos não houve progresso económico no Chile; ao invés disso, o regime ditatorial promoveu uma redistribuição selvagem do PIB". Desde o início do regime autoritário o consumo per capita de trigo caiu $8 \%$; do milho, $5 \%$; da carne, $15 \%$; do açúcar, $8,3 \%$; e do arroz, $14 \%$.

De qualquer forma, é preciso saber que os recentes resultados.econômicos favoráveis no Chile, quando comparados com a crise dos seus vizinhos democráticos, particularmente do Brasil e da Argentina, representam uma ameaça básica à democracia na América Latina. Na recente campanha política para plebiscito no Chile, o regime militar mostrou, em cadeia de televisão, comerciais retratando os problemas sociais e econômicos no Brasil e na Argentina, perguntando se é esse tipo de democracia que o povo chileno deseja.

SHEAHAN (1986, p.161) diz que as políticas econômicas características dos regimes autoritários na América Latina são controles de preço limitados, baixo índice de proteção, sérios esforços no sentido de limitar os déficits orçamentários, controles estritos dos salários, e condiçōes altamente favoráveis para investidores externos. Sheahan está confundindo discurso com ação efetiva. De fato, os regimes autoritários na América Latina não adotam necessariamente políticas económicas ortodoxas ou neoliberais; sua retórica é que é conservadora. Seu discurso é invariavelmente contra a intervenção estatal, contra o protecionismo e a favor da austeridade fiscal, embora nem sempre acreditem ou pratiquem o que afirmam. $O$ excessivo endividamento externo e os déficits públicos correspondentes dos anos 70 foram de responsabilidade dos regimes autoritários no Brasil, Argentina, Chile e Peru. Sheahan, porém, está certo ao preocupar-se com a sobrevivência dos governos não-autoritários na América Latina devido a políticas populistas que recrudesceram desde a redemocratização: elevaçōes irresponsáveis dos salários reais acima do crescimento da renda per capita, aumento das despesas públicas, e excessivo protecionismo. Sheahan fala

Neste momento há uma

incompatibilidade basica entre o pagamento integral dos juros sobre a divida e o crescimento com estabilidade de preços. 
também em "restrições indevidas ao investimento externo", mas estas restriçōes, no caso da nova Constituição Brasileira, por exemplo, são mais fruto da retórica nacionalista - afinal há retórica em todos os campos - do que de uma efetiva prática discriminatória.

Espero ter conseguido demonstrar neste artigo, através da crítica das políticas populistas e ortodoxas - porque afinal todas essas práticas e ideologias que examinamos podem ser reduzidas a essas duas categorias - o quanto sāo necessárias as políticas econômicas coerentes e racionais para a consolidação do regime democrático no Brasil, ou, mais amplamente, na América Latina. Sem equilíbrio orçamentário, equilibrio do balanço de pagamentos e estabilidade de preços é hoje praticamente impossível retomar o desenvolvimento econômico e lograr uma distribuição da renda mais justa.

No Brasil, o que estamos vendo hoje é o domínio de práticas populistas e ortodoxas, que ora se alternam, ora se somam. Em conseqüência, temos a estagnação económica e taxas muito altas de inflação, enquanto a renda continua a se concentrar. Nos primeiros seis meses do governo Sarney, durante o primeiro semestre de 1985 , tivemos uma política económica conservadora, que nāo funcionou. Em seguida uma política econômica, que se pretendia keynesiana e progressista, mas que afinal se revelou populista, levou o País, no primeiro semestre de 1987, com o fracasso do Plano Cruzado, a uma profunda crise económica e financeira. Em 1988, depois dos sete meses e meio em que estive encarregado da política económica brasileira, temos de volta as políticas económicas conservadoras. A direita volta a orientar a política económica. $O$ populismo, entretanto, continua presente, somando-se a uma ortodoxia totamente impotente para realizar a tarefa necessária para superar a crise económica do País. Hoje (outubro de 1988), o fracasso dessa política é evidente: a falta de credibilidade do governo e de crédito do Estado aprofunda-se, a taxa de inflação continua a acelerar-se, aproximando-se da hiperinflação, a taxa de investimento mantém-se muito baixa, a economia permanece estagnada, os salários reais estăo novamente declinando.

As políticas econômicas exigidas no Brasil nāo são de esquerda ou de direita. Essas distinçôes têm importância menor, considerando-se a gravidade da atual crise económica. Populismo e ortodoxia neoliberal estão hoje na base da crise fiscal do Estado, da dívida externa, da inflação, da reduçāo da taxa de investimentos. Esses problemas possuem tal magnitude hoje no Brasil que não é suficiente criticar o nacionalismo, o protecionismo, a recusa às políticas de ajustamento e o distributivismo da esquerda, o populismo e o clientelismo dos oportunistas, a ortodoxia, o conservadorismo social, o monetarismo, o liberalismo grosseiro e o internacionalismo subordinado da direita. Para se adotarem políticas econ6́micas pragmáticas, racionais e coerentes - que em certos momentos parecerão ortodoxas, em outros, heterodoxas -, serão necessárias nos homens públicos as qualidades de visão e coragem política. S6 assim será possível tomar as medidas - muitas delas impopulares, outras, certamente desagradáveis para as classes dominantes - que poderâo sanear as finanças do Estado brasileiro e permitir a retomada do desenvolvimento. A democracia está bem estabelecida no País, mas o contínuo fracasso do novo regime democrático em resolver alguns problemas económicos e sociais básicos representa um perigo que não pode ser subestimado. 
ALEJANDRO, C.D. 1981. Southern cone stabilization plans. In: CLINE, W. \& WEINTRAUB, S., eds. Economic Stabilization in developing countries. Washington, The Brookings Institution.

BRESSER PEREIRA, L.C. 1968. Desenvolvimento e crise no Brasil: 1930-1967. Rio de Janeiro, Zahar.

1970. Dividir ou multiplicar? A distribuição de renda e a recuperaçăo da economia brasileira. Visão, novembro.

- 1977. Estado e subdesenvolvimento industrializado. São Paulo, Brasiliense.

1978. O colapso de uma aliança de classes. São Paulo, Brasiliense.

1983. Seis interpretaçōes sobre o Brasil. Dados, 25(3).

1985. Pactos políticos. São Paulo, Brasiliense.

1987. Mudanças no padrāo de financiamento dos investimentos no Brasil. Revista de Economia Política, 7(4), outubro.

- 1988a. Uma estratégia alternativa para negociar a dívida externa. In: CONGRESSO DA LATIN AMERICAN STUDIES ASSOCIATION (LASA), Nova Orleans, março, 1988.

- 1988b. De volta ao capital mercantil: Caio Prado Jr. e a crise da Nova República. Revista Brasileira de Ciência Polficica, Universidade Federal de Brasilia, 1(1), maio.

CARDOSO, F.H. e FALETTO, E. 1970. Dependência e desenvolvimento na América Latina; ensino de interpretação sociológica. Rio de Janeiro, Zahar.

DINIZ, E. 1985. A transição polftica no Brasil: uma reavaliação da dinâmica da abertura. Dados, 28(3).

FAORO, R. 1988. Um Estado autenticamente militar desde 1930. Revista da Ordem dos Advogados do Brasil, São Paulo, (43/48):7, winter.

FERNANDES, F. 1985. Nova República? 3르 ed. Rio de Janeiro, Zahar.

LARA REZENDE, A. 1982. A política brasileira de estabilizaçāo: 1963/68. Pesquisa e Planejamento Econômico, 12(3), dezembro.

MAcPHERSON, C.B. 1966. The real world of democracy. New York, Oxford University Press.

MARTINS, L. 1983. Le regime autoritaire brésilien et la libèralization politique. Problèmes $d$ Amerique Latine, (65), juil./sept.

O'DONNELL, G. 1988. Hiatos, instituiçōes e perspectivas democráticás. In: WANDERLEY REIS, F. e O'DONNELL, G., eds. A democracia no Brasil: dilemas e perspectivas. São Paulo, Editora Revista dos Tribunais.

PIEDRA, M.P. 1988. El componente social del ajuste economico en America Latina. Santiago de Chile, ILDES, NU/CEPAL Center. (mimeografado).

RODRIGUES, M.U. 1988. O cruel "milagre" chileno. Folha de S.Paulo, 14 de setembro.

SHEAHAN, J. 1986. Economic policies and the prospects for successful transitions from authoritarian rule in Latin America. In: O'DONNELL, G. et alii. Transitions from authoritarian rule: comparative perspectives. Baltimore, John Hopkins University Press.

SCHWARTZMAN, S. 1988. A situaçāo atual da América Latina: os problemas-chave da democratização. São Paulo, Instituto de Estudos Avançados/USP.(mimeografado).

WANDERLEY REIS, F. 1988. Consolidação democrática e construçāo do Estado: In: WANDERLEY REIS, F. e O'DONNELL, G., eds. A democracia no Brasil: dilemas $e$ perspectivas. São Paulo, Editora Revista dos.Tribunais.

WEFFORT, F. C. 1984. Por que democracia? 2 ed., São Paulo, Brasiliense.

WERNECK, R.L.F. 1987. Empresas estatais e política macroeconômica. Rio de Janeiro, Editora Campus 


\section{Bibliografia}

BRESSER PEREIRA, L.C. Inflação inercial e Plano Cruzado. Revista de Economia Poliiica, 6(3), jul., 1986.

. Dívida externa: crise e soluções. São Paulo, Brasiliense, 1989.

CLINE, W. e WEINTRAUB, S., eds. Economic stabilization in developing countries. Washington, The Bronkings Institution, 1981.

O’DONNELL, G. Estado e alianças na Argentina, 1956-1976. Estudos CEBRAP. São Paulo, (21):33-76, jul./set. 1977.

O'DONNELL, G. et alii. Transitions from authoritarian rule: Latin America. Baltimore, John Hopkins University Press, 1986.

Transitions from authoritarian rule: comparative perspectives. Baltimore, John Hopkins University Press, 1986.

WANDERLEY REIS, F. e O'DONNEI L, G. A democracia no Brasil: dilemas e perspectivas. São Paulo, Editora Revista dos Tribunais, 1988.

Luiz Carlos Bresser Pereira é professor de Economia da Fundação Getúlio Vargas, São Paulo, e professor-visitante do Instituto de Estudos Avançados da USP. 